\title{
Income inequality, redistribution and the position of the decisive voter
}

\author{
Loek Groot ${ }^{1} \cdot$ Daan van der Linde ${ }^{1}$
}

Received: 17 July 2015 / Accepted: 16 May 2016 / Published online: 17 June 2016

(C) The Author(s) 2016. This article is published with open access at Springerlink.com

\begin{abstract}
A large literature explaining patterns of redistribution makes use of the median voter theorem. Using a novel approach, this contribution shows that in OECD countries the decisive voter, determined by the earner who sees her preferred tax rate being implemented, on average sits around the $50^{\text {th }}$ percentile in the income distribution, although significant within and between country differences exist. Under the assumption of a lognormal distribution of gross income, we derive the required tax rate to align the observed gross and net Gini coefficients in OECD countries. This estimated tax rate is compared to the tax rate preferred by the median income earner, which gives a new index capturing a nation's deviation from the median voter position, measured as the difference between the estimated percentile position of the decisive voter and the $50^{\text {th }}$ percentile position of the median voter. We provide a comparative overview of this index over time and between countries. We also locate the positions of alternative versions of the decisive voter, among which following the 'one dollar, one vote' rule, in a Lorenz curve diagram.
\end{abstract}

Keywords Redistribution · Lognormal distribution · Lorenz curve $\cdot$ Median voter theorem

\section{Introduction}

Rising levels of income and wealth inequality have recently led a number of authors to wonder why democracies have been unable to stall this process (e.g. Bonica et al. 2013). Piketty

Electronic supplementary material The online version of this article (doi: 10.1007/s10888-016-9333-7) contains supplementary material, which is available to authorized users.

Daan van der Linde

d.e.vanderlinde@uu.nl

Loek Groot

1.f.m.Groot@uu.nl

1 Utrecht University School of Economics, Kriekenpitplein 21-22, 3584 EC Utrecht, The Netherlands 
(2014, chapters 10 and 14) mentions that despite being a democracy, the Third Republic of France did not do much to curb rising inequality in the period before World War I. Standard economic models invoking the median voter theorem (henceforth MVT) predict rising inequality will be met with increased redistribution, yet faced with empirical evidence questioning this relation, recent work (e.g. the survey by Harms and Zink 2003) has put forth arguments claiming the political process may be skewed in favour of special interest groups (i.e. 'one-dollar-one-vote', Karabarbounis 2011) or distorted by institutions hampering the accountability of elected officials to the majority. Mettler (2011) claims information shortages hamper the translation of economic realities into political demands, whereas Mahler (2008) and Arawatari (2009) argue that skewed and decreasing voter turnout affect the representativeness of the electorate. Finally, multi-dimensional party manifestos, logrolling and coalition formation may give rise to deviations from the median voter rule.

The aim of this contribution is to locate the decisive voter in the income distribution in OECD nations. Using a new method, under a number of basic assumptions we show where in the income distribution the decisive voter sits. In our analysis, the decisive voter must be interpreted as the income earner who sees her most preferred tax rate being realized. Our approach builds on earlier work testing the validity of median voter theory, yet gives a more precise definition of the decisive voter compared to previous studies (see e.g. Scervini 2012 who classifies the median voter in between the $40^{\text {th }}$ and the $60^{\text {th }}$ percentile in the income distribution). Moreover, our positioning of the decisive voter is based on widely used data.

Our point of departure are the Gini coefficients for gross and net incomes from the OECD Income Distribution database (OECD 2015), which cover 32 countries for the period 1974 2012. If gross income is lognormally distributed, the country and year specific parameters of the lognormal distribution of income can be derived from the Gini coefficients and GDP per capita. We derive the optimal labour supply using the methodology from Roemer et al. (2003), giving the distribution of wages and labour supply and the formula for the tax rate and the lump sum transfer. We show that the preferred proportional tax rate is dependent on one's earnings capacity and identify the decisive voter as the one whose preferred tax rate is equal to the empirically estimated tax rate. Given the derived distribution for wages, we can locate the percentile position of the decisive voter. We find the decisive voter sits on average around the $50^{\text {th }}$ percentile in the income distribution, with significant differences within and between countries. ${ }^{1}$ We provide a comparative overview of these differences and pitch our outcomes against the predictions made by the MVT.

Assessing the position of the decisive voter in the income distribution requires a theoretical framework which is able to derive preferences for taxation, taking into account heterogeneity in wages and labour supply disincentives of taxes and transfers. Our approach is in line with the MVT subsumed under the Romer-Roberts-Meltzer-Richard model (henceforth RRMR, see Meltzer and Richard 1981), in which rising inequality in gross income increases the distance between the median earner and mean earner, increasing the desired level of redistribution by the median voter. This mechanism steers how changes in gross income inequality translate into net income inequality. According to the MVT, the decisive voter or median voter is the median earner under the assumptions that policy alternatives

\footnotetext{
${ }^{1}$ We applied the same model to the more comprehensive SWIID database and found that the decisive voter on average sits at the 60th percentile. However, as Jenkins (2015) has convincingly shown and two referees remarked, there are serious shortcomings in using the SWIID database for our purposes, particularly because of the imputation of Gini coefficients for (mostly) developing countries for which data are missing.
} 
can be situated along a one-dimensional political spectrum and that voters themselves have single-peaked preferences. Since we focus only on the gross and net income distribution, the mediating tax-and-transfer system is in line with a one-dimensional policy space in which voters have single-peaked preferences with respect to the parameters of the tax-and-transfer system.

Our approach has advantages and limitations. The most important advantage is that using only easily accessible statistics such as Gini coefficients, GDP per capita and government consumption as a share of GDP, our model provides an estimate of the position of the decisive voter. Second, we provide a way to include in-kind, non-cash public provision of goods such as public education in the model as one component of redistribution, alongside cash transfers. Third, we can precisely locate several hypothetical decisive voters in a Lorenz curve diagram, e.g. if the 'one dollar, one vote' rule applies, or the 'one man, one vote' rule, or when voters are myopic, solely focusing on net income and disregarding the disutility of labour. There are also some limitations to our approach. First, due to data limitations, we use the same labour supply elasticity for all OECD countries. With better data, for instance micro data including wage rates and working hours, the labour supply elasticity can be estimated for specific countries and years. Second, our assumption that gross income is lognormally distributed does not adequately describe the distribution of income at the right tail of high incomes (Singh and Maddala 1976). Although we are aware that the lognormality assumption has its limitations, it must be said that the high incomes are generally also underrepresented in surveys. A more serious shortcoming is that because the parameters of the lognormal distributions are derived from GDP per capita and the net and gross Gini coefficients, the resulting gross and net income distributions will be imperfectly mimicking the real distributions at the lower end of the income distribution. ${ }^{2}$ The assumption of lognormality to model the income distribution is frequently made, e.g. by Chotikapanich et al. (1997), Dikhanov and Ward (2002), Pinkovskiy and Sala-i-Martin (2009) and Van Zanden et al. (2014). Third, we assume the tax-and-transfer system can be described by the combination of a flat earnings tax and a uniform lump sum grant, while in reality there are a variety of taxes, ranging from wealth to capital income, VAT and excise taxes with differentiated rates, and a variety of welfare benefits, ranging from social assistance to housing benefits. Although capital income as part of GDP per capita is included in our parameter estimation, we abstract from capital (income) in our analytical model. Fourth, our estimates pertain only to countries generally classified as democratic, while results may differ for non-democratic nations which are not subject to the constraint that 'one man, one vote' has on the outcomes of the political process. Our findings are however indicative of the fact that even in these democratic nations the median income earner does not always coincide with the voter who sees her preferred level of redistributive taxation being realized.

This paper is organized as follows: Section 2 presents our theoretical model and the relation between preferred tax rates and wages. Section 3 provides information about the data used, the derivation of the lognormal distributions, the estimation of parameters and the analytical expressions of the percentile position of the decisive voter. We also provide a Lorenz curve diagram with the positions of the mean and median earners and several decisive voter positions depending on whether 'one man, one vote' or 'one dollar, one vote' applies. Section 4 contains the results. The final section summarizes and concludes.

\footnotetext{
${ }^{2}$ For instance, due to statutory minimum wages and the prevailing social benefit levels, there will be many more incomes at just these income levels than under the lognormal distributions.
} 


\section{Theoretical framework}

As is customary in the public economics literature, e.g. in the seminal article of Meltzer and Richard (1981), we model tax-and-transfer schemes by a proportional tax with tax rate $t$ and transfers $f$. While in reality tax and social security systems are complex, Roemer et al. (2003: 553) show for a subset of countries similar to ours such an assumption of affineness is suitable, as it 'is a very good description of the effective tax regime data for all the countries that we examine'. We assume $f$ consists of both a lump sum income transfer component $c$ and a public good component $g$. Heterogeneity is achieved by allowing individuals' wage rate $(w)$ and labour supply $(L)$ to differ. We use the same utility function as in Roemer et al. (2003), where utility is increasing in net disposable income $(y)$ and decreasing in labour supply:

$$
U(y, L)=y-\alpha L^{1+1 / \eta}
$$

with $\eta$ the wage elasticity of labour supply and $\alpha$ the parameter reflecting the disutility of labour. Maximizing utility given the budget constraint $y=(1-t) w L+c$, optimal labour supply is:

$$
L^{*}=\left[\frac{(1-t) w}{\widehat{\alpha}}\right]^{\eta}
$$

with $\hat{\alpha}=\alpha(1+1 / \eta)$. We assume a balanced budget implying $f=t \bar{x}$, with $\bar{x}$ representing mean gross income which using Eq. 2 can be stated as:

$$
c+g=t \int w L^{*} d F=t\left[\frac{1-t}{\widehat{\alpha}}\right]^{\eta} \int w^{1+\eta} d F=t\left[\frac{1-t}{\widehat{\alpha}}\right]^{\eta} \overline{w^{1+\eta}}
$$

so that the lump sum income transfer can be expressed as $c=t\left[\frac{1-t}{\hat{\alpha}}\right]^{\eta} \overline{w^{1+\eta}}-g$. The revenue-maximizing tax rate $t^{\max }$, which is optimal from a Rawlsian social justice perspective $^{3}$ is the one that maximizes $f$ (or $c$, if $g$ is exogenous). Maximizing Eq. 3 with respect to $t$ gives $t^{\max }=1 /(1+\eta)$.

To find the preferred tax rate $t_{i}$ of an individual with wage rate $w_{i}$, given the government balanced budget constraint, the indirect utility function, obtained by substituting Eqs. 2 and 3 into 1 , is differentiated with respect to $t$. This gives the relation between one's preferred tax rate and one's earnings capacity:

$$
t_{i}=\frac{w_{i}^{1+\eta}-\overline{w^{1+\eta}}}{w_{i}^{1+\eta}-(1+\eta) \overline{w^{1+\eta}}}
$$

depicted in Fig. 1, for different labour supply elasticities. For higher values of $\eta$, the revenue maximizing tax rate $1 /(1+\eta)$ shifts to the left. Since the preferred tax rate is positive for all those with earning capacity $w_{i}^{1+\eta}$ below $\overline{w^{1+\eta}}$, the median wage earner $w_{m}^{1+\eta}<\overline{w^{1+\eta}}$ will choose a positive tax rate, which is higher, the lower the labour supply elasticity.

Using Eq. 4, as the first derivative of $t$ with respect to $w$ is negative, the higher one's wage rate becomes, the lower the preferred tax rate will be. The first derivative of $t$ with

\footnotetext{
${ }^{3}$ It is the preferred tax rate for those with zero earning capacity, because it maximizes the lump sum transfer.
} 


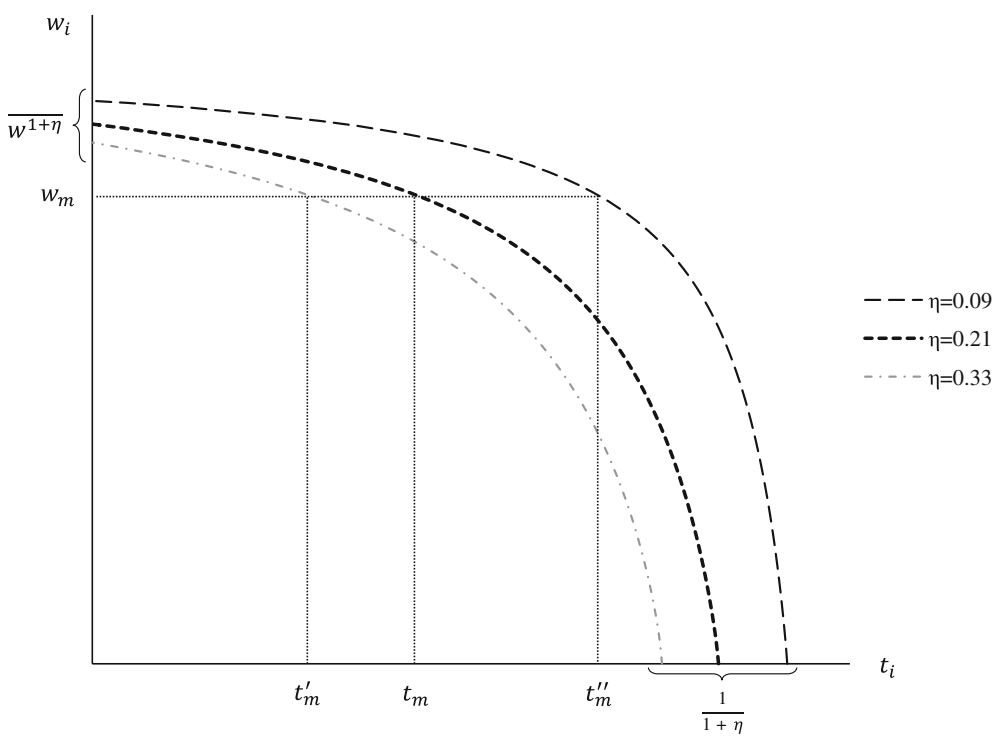

Fig. 1 The relationship between the preferred tax rate and earnings capacity. Median preferred tax rates are given for three different wage elasticities of labour supply

respect to $\overline{w^{1+\eta}}$ is positive, so given one's wage rate, the higher the wages economy-wide, the higher the tax rate chosen. The tax rate $t_{m}$ preferred by the median earner with $w_{m}$ is:

$$
t_{m}=\frac{w_{m}^{1+\eta}-\overline{w^{1+\eta}}}{w_{m}^{1+\eta}-(1+\eta) \overline{w^{1+\eta}}} .
$$

We can rewrite Eq. 4, giving the wage rate as a function of the preferred tax rate:

$$
w_{i}=\left[\frac{1-t_{i}(1+\eta)}{\left(1-t_{i}\right)} \bar{w}^{1+\eta}\right]^{\frac{1}{1+\eta}} .
$$

Inserting our estimates of tax rates $\hat{t}$ that align observed country- and year-specific gross and net Gini coefficients in Eq. 6 allows us to identify the decisive wage earner with wage rate $\hat{w}_{D}$ :

$$
\hat{w}_{D}=\left[\frac{1-\hat{t}(1+\eta)}{(1-\hat{t})} \overline{w^{1+\eta}}\right]^{\frac{1}{1+\eta}} .
$$

In the introduction, we already gave a limitative list of reasons why the observed tax rate may diverge from the one expected under MVT. Here we want to add another possibility, namely that the voter is not maximizing utility $U$ but net income $y$, which analogous to Eqs. 5 and 6 results in a preferred tax rate:

$$
t_{i}^{\prime}=\frac{(1+\eta) w_{i}^{1+\eta}-\overline{w^{1+\eta}}}{(1+\eta)\left(w_{i}^{1+\eta}-\overline{w^{1+\eta}}\right)}
$$

and

$$
\hat{w}_{D}^{\prime}=\left[\frac{1-\hat{t}(1+\eta)}{(1-\hat{t})(1+\eta)} \overline{w^{1+\eta}}\right]^{\frac{1}{1+\eta}} .
$$




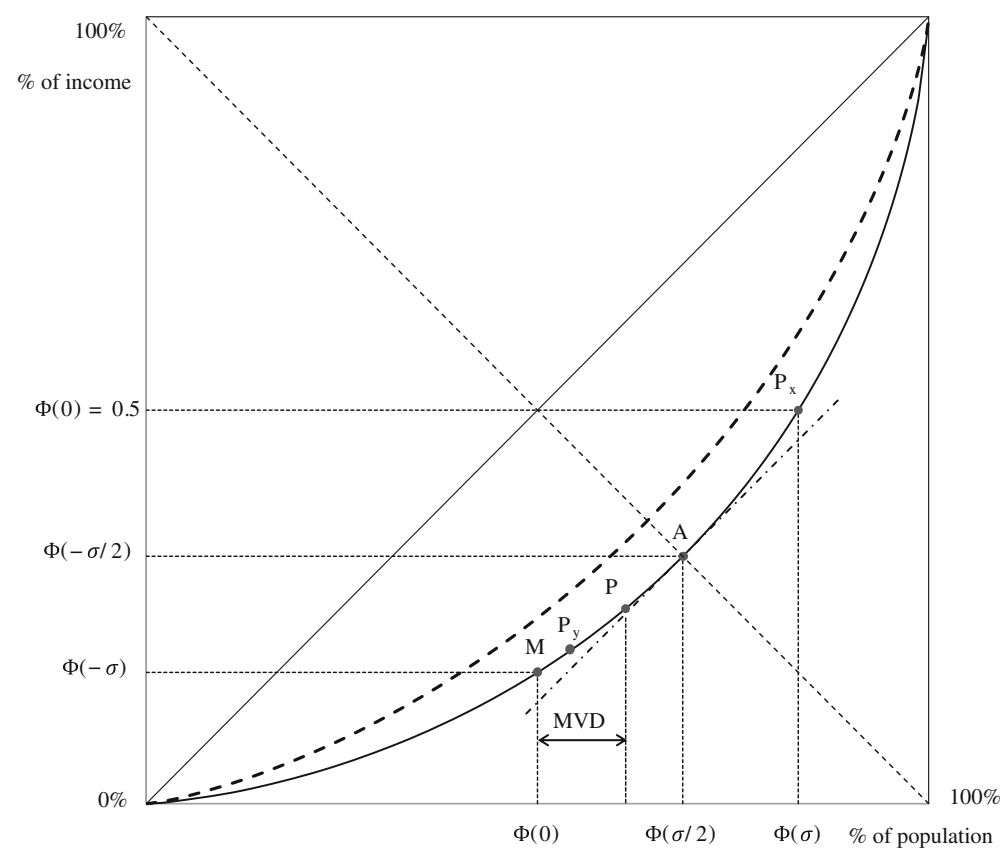

Fig. 2 Lorenz curves for the USA in 2012. The solid line represents the gross distribution with $\mu=10.34$, $\sigma=0.97$ and $G=0.51$; the dashed line represents the net distribution with $\mu_{n}=10.37, \sigma_{n}=0.72$ and $G_{n}=0.39$

Since the ratio $\hat{w}_{D}^{\prime}(\hat{t}) / \hat{w}_{D}(\hat{t})$ is below unity, the percentile position of this 'myopic' decisive voter, denoted by $P_{y}$ in the income distribution will thus be lower than $P$, corresponding to the percentile position of $\hat{w}_{D}$ (see also Fig. 2).

\section{Data and method}

In order to locate the decisive voter $\hat{w}_{D}$ by country and year, we need information on the wage distribution and imposed tax rate in a country. We assume that income follows a lognormal distribution. Compared to more complex distributions with two or more parameters, the lognormality assumption may bias our estimates of both mean income and dispersion of income upwards (McDonald 1984). Combining data from the OECD Income Distribution database (OECD 2015) on market or gross income Gini coefficients ${ }^{4}(G)$ and post-tax-andtransfer or net Gini $\left(G_{n}\right)$ with GDP per capita (in current international dollars at PPP) data from the World Bank (2015), we can estimate the parameters of the lognormal distribution of gross and net income. For cases with missing data for GDP or population, we standardize GDP per capita to $1000 .^{5}$

\footnotetext{
${ }^{4}$ Our gross and net Gini measures are based on household market and disposable income per equivalent household member, according to the 2011 income definition, adjusting income by the square root of the household size. OECD figures are based on survey data and for some countries breaks in the series prevent comparability over time. See OECD (2015) for more details.

${ }^{5}$ While mean income measured as GDP per capita or measured from survey means may significantly differ (see e.g. Milanovic 2002), under our assumption of lognormality our estimates of the tax rate are independent
} 
With gross income $x$ lognormally distributed, $x \sim L N\left(\mu, \sigma^{2}\right), \mu$ and $\sigma$ can be estimated using $G$ and mean per capita income $\bar{x}$. If the income distribution is lognormal, the Gini only depends on the standard deviation parameter $\sigma$, according to $G=2 \Phi(\sigma / \sqrt{2})-1$, where $\Phi$ represents the cumulative density function of the standard normal distribution (see Aitchison and Brown 1957: 13 and Chotikapanich et al. 1997: 536). For an observed Gini $G$ in a specific country and year:

$$
\sigma=\sqrt{2} \Phi^{-1}((G+1) / 2) .
$$

Additionally, for GDP per capita equal to $\bar{x}$, the $\mu$ parameter of the country-specific lognormal gross income distribution is given by:

$$
\mu=\ln \bar{x}-\sigma^{2} / 2 .
$$

In order to retrieve the distribution of disposable net income $(y)$ on which net Gini $\left(G_{n}\right)$ is based, we make a distinction between the (minimal) required tax rate $t_{g}$ to finance public goods $g$ and the tax rate $t-t_{g}$ required to finance the per capita lump sum income transfer $c$. One can think of $t_{g}$ as the required tax rate in case $c=0$. For the mean income earner, it must be the case that $t_{g} \bar{x}=g$ and $\left(t-t_{g}\right) \bar{x}=c$. So $\bar{y}=(1-t) \bar{x}+c=(1-t) \bar{x}+\left(t-t_{g}\right) \bar{x}=$ $\left(1-t_{g}\right) \bar{x}$. This basically amounts to tax revenues used to provide public goods driving a wedge between average gross and net income, while tax revenues used for redistribution, the disbursement of $c$, do not. For $t_{g}$ we use country- and year-specific general government final consumption expenditure as a fraction of GDP, taken from the World Bank (2015). ${ }^{6}$ Disposable net income is distributed according to $y \sim L N\left(\mu_{n}, \sigma_{n}^{2}\right)$, where by applying Eqs. 10 and 11 and using $G_{n}$ and $\bar{y}$ we can derive the parameters for $\sigma_{n}$ and $\mu_{n}$. The values of these parameters are of course determined by the real, but unobserved, tax-andtransfer systems in a country in a particular year that shaped the net income distribution. ${ }^{7}$ In Appendix 1, given $\mu$ and $\sigma$, we derive the parameters $\sigma_{n}$ and $\mu_{n}$ as a function of the tax rates analytically. The correlation of the corresponding simulated net Gini and the real observed net Gini from OECD (2015) is 0.993.

Under the assumption of a flat tax, lump sum transfer system, given the derived distributions of gross and net income, we can estimate $\hat{t}$ by making use of the properties of the lognormal distribution. In a distribution regression function: ${ }^{8}$

$$
y_{i}=\underbrace{\frac{\operatorname{Cov}(x, y)}{\operatorname{Var}(x)}}_{1-\hat{t}} x_{i}+\underbrace{\bar{y}-\frac{\operatorname{Cov}(x, y)}{\operatorname{Var}(x)} \bar{x}}_{\hat{c}} .
$$

\footnotetext{
of the mean. Differences between both measurements of mean income would play out in our estimates for the (lump sum) government transfers, yet here these are only of secondary interest.

${ }^{6}$ This measure consists of 'general government final consumption expenditure (formerly general government consumption) includes all government current expenditures for purchases of goods and services (including compensation of employees). It also includes most expenditures on national defense and security, but excludes government military expenditures that are part of government capital formation' (World Bank 2015).

${ }^{7}$ For a non-linear tax schedule, Lubrano (2015: 23) remarks that it has been observed that in many countries the tax schedule can be approximated by $T(x)=x-a x^{b}$, so disposable income $y$ can be expressed as $y=x-T(x)=a x^{b}$. A nice property of the lognormal distribution is that if $x \sim L N\left(\mu, \sigma^{2}\right)$, then $a x^{b} \sim$ $L N\left(b \mu+\ln a, b^{2} \sigma^{2}\right)$, so disposable income is also lognormally distributed.

${ }^{8}$ Alternatively, Roemer et al. (2003: 553) using micro survey data run a regression $y=a+b x$, where similarly the obtained regression coefficient $b$ equals $1-\hat{t}$ and coefficient $a$ equals $\hat{c}$.
} 
Table 1 The lognormal distribution of gross income $(x)$, wages $(w)$ and optimal labour supply $\left(L^{*}\right)$ and the expressions of the median and mean values

\begin{tabular}{lll}
\hline$x \sim L N\left(\mu, \sigma^{2}\right)$ & $w \sim L N\left(\mu, \sigma^{2} /(1+\eta)^{2}\right)$ & $L^{*} \sim L N\left(0,[\eta \sigma /(1+\eta)]^{2}\right)$ \\
\hline$x_{m}=e^{\mu}$ & $w_{m}=x_{m}=e^{\mu}$ & $L_{m}^{*}=e^{0}=1$ \\
$\bar{x}=e^{\mu+\sigma^{2} / 2}$ & $\bar{w}=e^{\mu+[\sigma /(1+\eta)]^{2} / 2}$ & $\bar{L}^{*}=e^{[\eta \sigma /(1+\eta)]^{2} / 2}$ \\
\hline
\end{tabular}

Under $t=\hat{t}$, see Appendix 1 for distributions under alternative tax rates

The predicted tax rate $\hat{t}$ is thus given by the following equation:

$$
\hat{t}=\frac{\operatorname{Var}(x)-\operatorname{Cov}(x, y)}{\operatorname{Var}(x)}
$$

with

$$
\operatorname{Var}(x)=\left(e^{\sigma^{2}}-1\right) e^{2 \mu+\sigma^{2}}
$$

and the covariance of two lognormally distributed variables:

$$
\operatorname{Cov}(x, y)=E(x y)-E(x) E(y)=e^{\mu+\mu_{n}+\left(\sigma^{2}+\sigma_{n}^{2}+2 \rho \sigma \sigma_{n}\right) / 2}-e^{\mu+\mu_{n}+\left(\sigma^{2}+\sigma_{n}^{2}\right) / 2} .
$$

We choose to set $\rho=1$, which amounts to the simplifying assumption that the tax-andtransfer system does not change the rank one has in the gross and net income distributions. ${ }^{9}$ Given $\bar{y}, \bar{x}$ and $\hat{t}, \hat{c}$ follows from:

$$
\hat{c}=\bar{y}-\frac{\operatorname{Cov}(x, y)}{\operatorname{Var}(x)} \bar{x}=e^{\mu_{n}+\sigma_{n}^{2} / 2}-(1-\hat{t}) e^{\mu+\sigma^{2} / 2}=e^{\mu_{n}+\sigma_{n}^{2} / 2}\left[1-\frac{\left(e^{\sigma \sigma_{n}}-1\right)}{\left(e^{\sigma^{2}}-1\right)}\right] .
$$

Departing from the lognormal distribution of gross income, we can derive the distributions of wages, labour supply and the distribution of net income as a function of the tax rate. In order to retrieve the wage distribution, and in line with Roemer et al. (2003: 549), we first calibrate $\alpha$ so the labour supply $L_{m}$ of the median earner is normalized to one, so $x_{m}=L_{m} w_{m}=w_{m}$. Using Eq. 2, this implies $\hat{\alpha}=(1-\hat{t}) w_{m}=(1-\hat{t}) e^{\mu}$.

We can now derive $w_{i}$ by inverting gross income $x_{i}=w_{i} L_{i}^{*}=\left[\frac{1-\hat{t}}{\hat{\alpha}}\right]^{\eta} w_{i}^{1+\eta}$ :

$$
w_{i}=\left[\left(\frac{1-\hat{t}}{\hat{\alpha}}\right)^{-\eta} x_{i}\right]^{\frac{1}{1+\eta}}=\left[\left(\frac{1}{w_{m}}\right)^{-\eta} x_{i}\right]^{\frac{1}{1+\eta}}=\left[e^{\eta \mu} x_{i}\right]^{\frac{1}{1+\eta}} .
$$

In general, if $x \sim L N\left(\mu, \sigma^{2}\right)$ then $a x^{b} \sim L N\left(b \mu+\ln a, b^{2} \sigma^{2}\right)$, so the distribution of wages is also lognormal since the RHS of Eq. 17 is of the form $w_{i}=a x_{i}^{b}$, with $a=e^{\eta \mu /(1+\eta)}$ and $b=1 /(1+\eta)$. The distribution of wages is then given by $w \sim L N\left(\mu, \sigma^{2} /(1+\eta)^{2}\right)$. Analogously, again using Eq. 2 and the parameters of the lognormal wage distribution, optimal labour supply ${ }^{10}$ under $\hat{t}$ is lognormally distributed as $L^{*} \sim L N\left(0,[\eta \sigma /(1+\eta)]^{2}\right)$. Using the properties for the median and average of the lognormal distribution, Table 1 summarizes mean and median levels of gross income, wages and labour supply.

\footnotetext{
${ }^{9}$ This assumption is strong, as empirical work has shown in reality tax systems do re-rank households or individuals (see e.g. Jenkins 1988; Aronson et al. 1994).

${ }^{10}$ Since median labour supply under $\hat{t}$ is normalized to 1 , if the tax rate is lowered, then median labour supply is higher than 1.
} 
Table 2 Income levels and corresponding income and population shares of the median and average earner, the 'one dollar, one vote' earner and the decisive voter

\begin{tabular}{llll}
\hline Variable & Level & Population share $(p)$ & Income share $(s)$ \\
\hline$x_{m}$ & $e^{\mu}$ & $\Phi(0)=0.5$ & $\Phi(-\sigma)$ \\
$\bar{x}$ & $e^{\mu+\sigma^{2} / 2}$ & $\Phi(\sigma / 2)$ & $\Phi(-\sigma / 2)$ \\
$P_{x}$ & $e^{\mu+\sigma^{2}}$ & $\Phi(\sigma)$ & $\Phi(0)=0.5$ \\
$P$ & $e^{-\eta \mu} \hat{w}_{D}^{1+\eta}$ & $\Phi\left[(1+\eta)\left(\ln \hat{w}_{D}-\mu\right) / \sigma\right]$ & $\Phi\left[(1+\eta)\left(\ln \hat{w}_{D}-\mu-\sigma^{2}\right) / \sigma\right]$ \\
$P_{y}$ & $e^{-\eta \mu} \hat{w}_{D}^{\prime 1+\eta}$ & $\Phi\left[(1+\eta)\left(\ln \hat{w}_{D}^{\prime}-\mu\right) / \sigma\right]$ & $\Phi\left[(1+\eta)\left(\ln \hat{w}_{D}^{\prime}-\mu-\sigma^{2}\right) / \sigma\right]$ \\
\hline
\end{tabular}

$p$ is the (abscissa) percentile position of the Lorenz curve on the horizontal axis, $s$ is the (ordinate) percentile position of the Lorenz curve on the vertical axis

One further simplification following from the lognormality assumption of gross and net income is that by rewriting Eq. 5 the preferred tax rate by the median earner becomes a function of the variance in gross income $\sigma^{2}$ :

$$
t_{m}=\frac{1-e^{\sigma^{2} / 2}}{1-(1+\eta) e^{\sigma^{2} / 2}} .
$$

In general, the coordinates of points $F(x) ; L(x)$ of the Lorenz curve generated by a lognormal distribution of $x \sim L N\left(\mu, \sigma^{2}\right)$ can be stated as $\Phi((\ln x-$ $\mu) / \sigma) ; \Phi\left(\left(\ln x-\mu-\sigma^{2}\right) / \sigma\right)$. Using the parameters of the distribution of $w$, the percentile position in which the decisive gross (and net) wage earner $\hat{w}_{D}$ sits (denoted by $P$ ) is then given by its first coordinate:

$$
P=\Phi\left(\frac{(1+\eta)\left(\ln \hat{w}_{D}-\mu\right)}{\sigma}\right) .
$$

Our index of the median voter deviation (MVD) relates the percentile position $P$ of the decisive voter $\hat{w}_{D}$ in the income distribution to that of the median earner $w_{m}$ :

$$
\mathrm{MVD}=P-0.5 .
$$

Figure 2 depicts a Lorenz curve diagram, using the parameters of the USA in 2012. If the MVT were to hold, the decisive voter would be located in point $M$, with its abscissa equal to $50 \%$ (i.e., the median). We contrast it to our account of 'one dollar, one vote', in which income determines the voting outcome. Our operationalization of 'one dollar, one vote' differs from Karabarbounis (2011). In his account, since every dollar is a vote, an increase in the income of any group of voters relative to the mean tilts redistributive taxes closer to their preferred level. In our account, 'one dollar, one vote' entails that taxes are set at the level preferred by the individual located around a share of half of total income. Thus if 'one dollar, one vote' holds, then $P$ would coincide with point $P_{x}$, with its ordinate equal to $50 \%$, where half of total income is earned by those below this point. Point $A$ denotes the location of the average earner, where the slope of the Lorenz curve is unity, so parallel to the line of equality. $P_{x}$ is always located to the right of both $M$ and $A, M$ is always to the left of $A$ and the decisive myopic voter $P_{y}$ is always to the left of $P_{x}$ yet the location of $M, A$, $P_{y}$ and $P_{x}$ relative to our estimation of the location of the decisive voter $P$ is an empirical question which we address below.

Table 2 gives the coordinates of these points $M, A, P_{x}, P$ and $P_{y}$. The gross income level of the median earner is equal to $e^{\mu}$. The income share $s$ of all those earning up to the 
median income can be calculated using the formula for the incomplete first moment of the lognormal distribution:

$$
\int_{0}^{z} x f(x) d x=e^{\mu+\sigma^{2} / 2} \Phi\left(\frac{\ln z-\mu-\sigma^{2}}{\sigma}\right) .
$$

so the income share is:

$$
s\left(x_{m}\right)=\frac{\int_{0}^{x_{m}} x f(x) d x}{\int_{0}^{\infty} x f(x) d x}=\frac{\int_{0}^{e^{\mu}} x f(x) d x}{\bar{x}}=\frac{e^{\mu+\sigma^{2} / 2} \Phi\left(\frac{\ln e^{\mu}-\mu-\sigma^{2}}{\sigma}\right)}{e^{\mu+\sigma^{2} / 2}}=\Phi(-\sigma) .
$$

The income share is equivalent to the ordinate of the Lorenz curve, that is, the percentile position on the vertical axis. The abscissa $(p)$ of the median earner is by definition 0.5 or $50 \%$. In a similar way, the income and population shares for the income earners $A$ and $P_{x}$ can be derived. For the coordinates of the decisive voter $P$, its gross income is $\hat{x}_{D}=\hat{w}_{D} L^{*}=\hat{w}_{D}^{1+\eta}\left(\frac{1-\hat{t}}{\hat{\alpha}}\right)^{\eta}=\hat{w}_{D}^{1+\eta} e^{-\eta \mu} .{ }^{11}$ Since the lognormal distribution has the property that its corresponding Lorenz curve is symmetrical seen from the socalled 'alternative diagonal', the Lorenz asymmetry coefficient (Damgaard and Weiner 2000) defined as the sum of the Lorenz curve abscissa and ordinate at the mean earner (see the second row in Table 2) must be equal to 1 .

To take stock, the assigned decisive voter according to the MVT is at the $50^{\text {th }}$ percentile, according to the 'one dollar, one vote' it is $P_{x}$, based on the tax rate that aligns gross and net Ginis it is $P$ and the net income maximizing voter predicts $P_{y}$. In the following section, we will investigate the positioning of the various decisive voters identified into more detail.

\section{Results}

The position of the decisive voter in our method is of course dependent on the imposed wage elasticity of labour supply $\eta$, which determines the labour supply disincentives of higher taxation. In general, the higher the labour supply elasticity, the lower the tax revenues for a given tax rate. We assume the labour supply elasticity is constant across time and across countries. While this assumption is not unreasonable for men, where most studies find low $\eta$-values that do not largely differ between countries, findings for females exhibit higher values and more cross country variation. We take the weighted mean of 205 estimates of wage elasticity of labour supply for men and women in meta-regressions by Evers et al. (2008, see especially their Tables 1 and 2 for the countries considered) based on studies of the uncompensated wage elasticity for a large number of OECD countries, leading us throughout the following analysis to present findings with $\eta$ equal to 0.21 . The online appendix elaborates on the findings for different values of $\eta$.

Our method yields 320 country-year-specific values for $P, P_{x}$ and $P_{y}$. For $P$, the two extremes are Finland $(P=0.28$ in 1994) and Chile $(P=0.68$ in 2006), with the average position of the decisive voter equal to 0.50 and an overall standard deviation of 0.07 . As can be noted from Table 3, the between-country variance $(0.07)$ is about twice as high as the within country variance (0.03). The largest within-country deviations occurred in Sweden, Finland and Ireland. According to Table 3 and illustrated in Fig. 3, the position $P_{y}$ of the

\footnotetext{
${ }^{11} \mathrm{Using} \overline{w^{1+\eta}}=x_{m}^{\eta} \bar{x}$, the gross income of the decisive voter as a function of the tax rate can be expressed as $\hat{x}_{D}=\frac{1-\hat{t}(1+\eta)}{1-\hat{t}} \bar{x}$.
} 
Table 3 Summary statistics for $P, P_{y}$ and $P_{x}$

\begin{tabular}{llllll}
\hline & Mean & SD & Min & Max \\
\hline$P_{y}$ & Overall & 0.42 & 0.07 & 0.21 & 0.61 \\
& - Between & & 0.07 & & \\
& - Within & & 0.03 & & 0.68 \\
$P$ & Overall & 0.50 & 0.07 & 0.28 & \\
& - Between & & 0.07 & & 0.87 \\
& - Within & & 0.03 & & \\
$P_{x}$ & Overall & 0.81 & 0.03 & 0.73 & \\
& - Between & & 0.03 & & \\
& - Within & & 0.01 & & \\
& & &
\end{tabular}

Based on $N=320$ country-year observations for 33 countries, so on average 10 year-observations per country

'myopic' decisive voter maximizing net income is lower than $P$. This follows from the comparison of Eqs. 7 and 9, which shows the wage and income level of the myopic incomemaximizing decisive voter $\hat{w}_{D}^{\prime}(\hat{t})$ will always lie below $\hat{w}_{D}(\hat{t})$. The position of $P_{x}$, such that $50 \%$ of total gross income is below that point, has a range of only 14 percentile points. Due to lack of space to present results for all three percentile positions and since $P$ sits nicely between $P_{y}$ and $P_{x}$, in what follows we will concentrate on $P$.

Table 4 provides the descriptive statistics for $P$ for all OECD nations, showing the average decisive percentile $\bar{P}$ for each country, with its respective standard deviations, minimum and maximum and number of observations.

The MVT suggests that the median voter will be decisive in setting the tax rate. Table 4 however suggests that the MVT does not consistently apply across OECD countries. For instance, in Chile and the United States, the decisive voter is well above the median

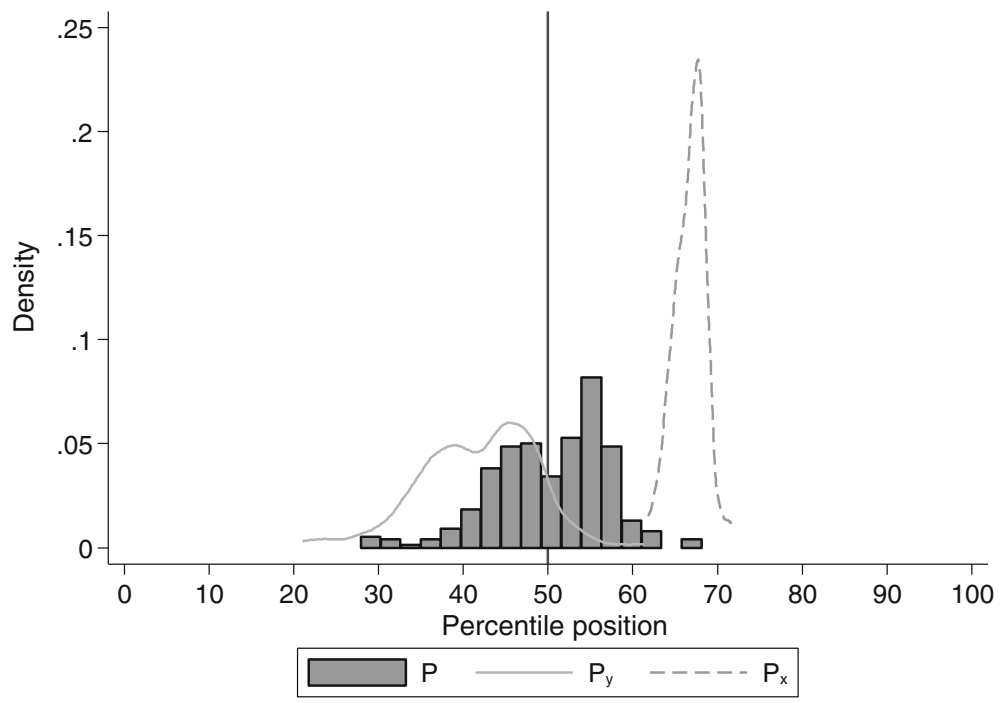

Fig. 3 Distribution of $P, P_{y}$, and $P_{x}$ 
Table 4 Summary statistics for $P$ by country

\begin{tabular}{|c|c|c|c|c|c|}
\hline & Mean & SD & Min & Max & $\mathrm{N}$ \\
\hline Australia & 0.56 & 0.01 & 0.54 & 0.57 & 6 \\
\hline Austria $^{a}$ & 0.47 & 0.01 & 0.46 & 0.49 & 9 \\
\hline Belgium $^{a}$ & 0.44 & 0.02 & 0.41 & 0.47 & 9 \\
\hline Canada & 0.54 & 0.02 & 0.50 & 0.56 & 36 \\
\hline Chile $^{\mathrm{a}}$ & 0.68 & 0.00 & 0.68 & 0.68 & 3 \\
\hline Czech Republic & 0.45 & 0.01 & 0.44 & 0.47 & 11 \\
\hline Denmark & 0.41 & 0.02 & 0.36 & 0.44 & 11 \\
\hline Estonia & 0.55 & 0.02 & 0.52 & 0.57 & 9 \\
\hline Finland & 0.39 & 0.05 & 0.28 & 0.46 & 27 \\
\hline France & 0.48 & 0.01 & 0.46 & 0.49 & 7 \\
\hline Germany & 0.48 & 0.01 & 0.45 & 0.49 & 9 \\
\hline Greece & 0.54 & 0.02 & 0.51 & 0.57 & 8 \\
\hline Iceland & 0.49 & 0.03 & 0.44 & 0.54 & 9 \\
\hline Ireland $^{\mathrm{a}}$ & 0.48 & 0.05 & 0.41 & 0.55 & 9 \\
\hline Israel & 0.55 & 0.04 & 0.48 & 0.59 & 9 \\
\hline Italy & 0.54 & 0.01 & 0.52 & 0.56 & 10 \\
\hline Japan & 0.57 & 0.01 & 0.56 & 0.58 & 6 \\
\hline Korea & 0.58 & 0.00 & 0.58 & 0.58 & 7 \\
\hline Luxembourg & 0.50 & 0.01 & 0.48 & 0.51 & 9 \\
\hline Netherlands & 0.49 & 0.02 & 0.46 & 0.53 & 12 \\
\hline New Zealand & 0.56 & 0.02 & 0.51 & 0.57 & 8 \\
\hline Norway & 0.46 & 0.02 & 0.45 & 0.49 & 8 \\
\hline Poland $^{\mathrm{a}}$ & 0.54 & 0.02 & 0.53 & 0.58 & 9 \\
\hline Portugal $^{\mathrm{a}}$ & 0.57 & 0.02 & 0.54 & 0.60 & 9 \\
\hline Russia & 0.62 & 0.01 & 0.61 & 0.63 & 2 \\
\hline Slovakia & 0.48 & 0.02 & 0.46 & 0.51 & 9 \\
\hline Slovenia & 0.43 & 0.01 & 0.42 & 0.45 & 9 \\
\hline Spain $^{\mathrm{a}}$ & 0.56 & 0.01 & 0.55 & 0.57 & 9 \\
\hline Sweden & 0.39 & 0.07 & 0.29 & 0.47 & 10 \\
\hline Switzerland $^{\mathrm{a}}$ & 0.57 & 0.00 & 0.57 & 0.57 & 2 \\
\hline Turkey & 0.63 & 0.00 & 0.63 & 0.63 & 2 \\
\hline United Kingdom & 0.55 & 0.02 & 0.51 & 0.58 & 16 \\
\hline United States & 0.60 & 0.01 & 0.57 & 0.61 & 11 \\
\hline
\end{tabular}

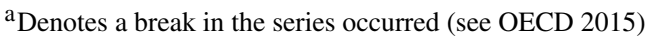

position, whereas in the Scandinavian countries it is well below the median. In a political system in which 'one dollar, one vote' would rule, higher market income inequalities would not be positively, but rather negatively associated with levels of taxation, implying higher inequalities lead to lower elected tax rates. In terms of the Lorenz curve diagram of Fig. 2, increasing inequality corresponds to an outward shift of the Lorenz curve and a higher percentile position of $P_{x}$, hence a lower elected tax rate. 


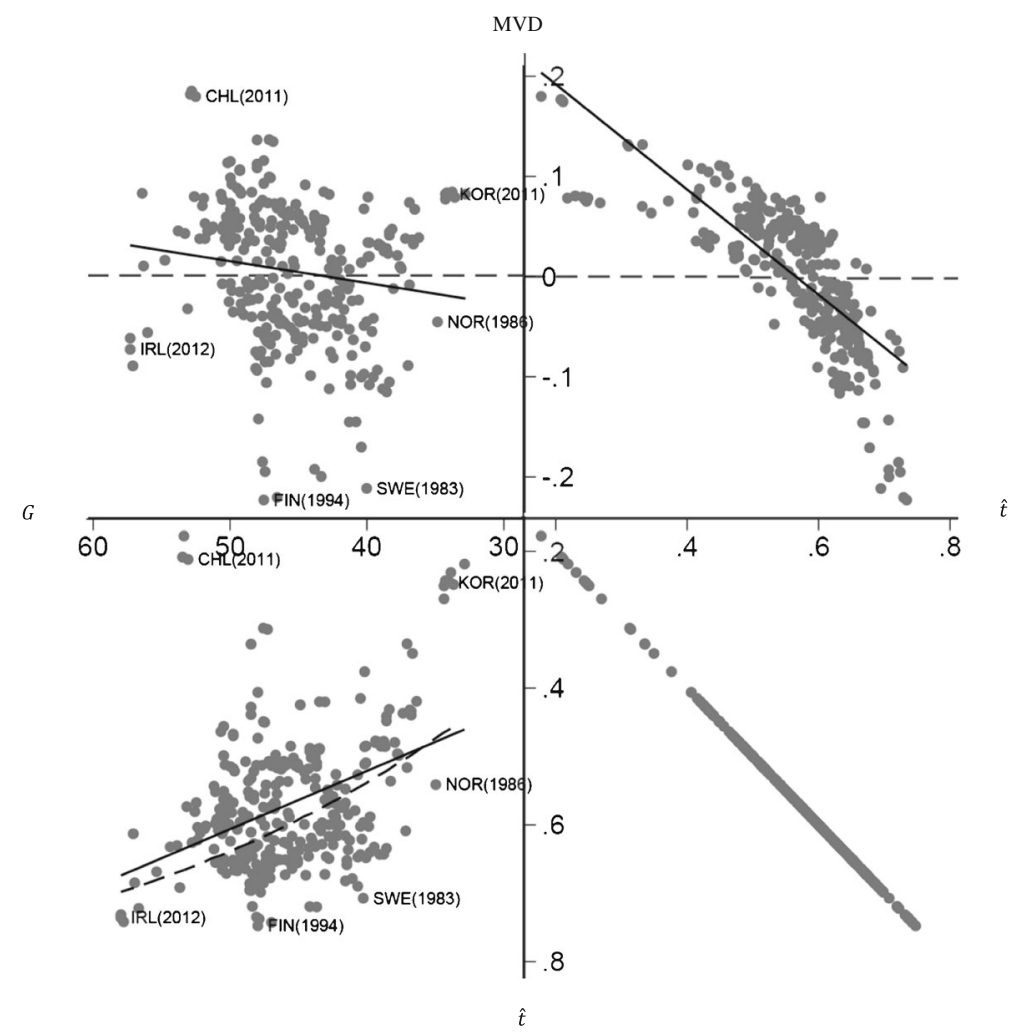

Fig. 4 Quadrant diagram with $\hat{t}$, median voter deviation (MVD) and gross Gini G, with dashed lines indicating the relations under RRMR

Figure 4 allows us to study these associations, giving the relationship between the MVD, the elected tax rate $\hat{t}$ and gross income inequality measured by the Gini coefficient along four quadrants. The dashed lines depict the situation when MVT impeccably holds. The bottom left quadrant depicts the relationship between gross income inequality and the elected tax rate and the best fitting line. Chile is a notable outlier, combining high inequality with a low tax rate, while South Korea combines low inequality with a low tax rate. The RRMR model predicts the elected tax rate to move in the direction of the revenue-maximizing tax rate $\left(t^{\mathrm{max}}\right)$ as gross income inequality is higher, i.e. the larger the difference between the median earner and mean earner, the more there is to gain for the median earner by voting for a higher tax rate. We find a positive relationship as expected, yet with a relatively low correlation $(\rho=0.39)$. While generally nations with higher gross income inequalities face higher tax rates, the low correlation implies that in some countries high income inequalities persist in the distribution of disposable income as they are not met with higher tax rates and transfers. The explanation for this weak association is to be found in the top left quadrant of Fig. 4, which shows higher gross income inequalities are weakly associated with higher (and positive) median voter deviations $(\rho=0.15)$. As indicated in the figure, Sweden and Finland are notable outliers here. 
Finally, in the top right quadrant of Fig. 4 we find a strong negative association between the MVD and $\hat{t}$, which in itself is not surprising, as the MVD is a function of $P$ (see Eq. 20) and $P$ in turn is determined by $\hat{t}$. In states where the MVD is lower, the tax rate is closer to the revenue-maximizing tax rate $(\rho=-0.78)$. Within the class of countries marked by a positive MVD, the variance is higher, so some countries do implement sizeable tax-andtransfer programs, while others do not.

In sum, if the MVT holds impeccably, then a much stronger positive relationship between market income inequality and the tax rate would be expected in the bottom left quadrant, with the MVD in the top quadrants always equal to zero, indicated by the dashed lines. The scatter plots in the upper quadrants illustrate that the MVD does not oscillate around zero, which suggests deviations from RRMR, that is large variations from the expected tax-and-transfer schemes. The RRMR framework thus seems unable to fully predict the cushioning effect of taxation and redistribution, especially for nations with relatively high market income inequality.

A second test of the RRMR model is provided by employing our model to simulate a world in which the RRMR hypothesis would perfectly hold. If throughout the OECD, the electoral systems did ensure political accountability towards the median voter, the decisive voter would coincide with the median earner at the $50^{\text {th }}$ percentile in the income distribution, selecting tax rate $t_{m}$ which maximizes her utility. For any $t_{m}$, we can simulate net income inequality (see Appendix 1) and find the relationship between simulated net income inequality under MVT and observed gross income inequality, both measured by Gini coefficients, as shown in Fig. 5. In the same figure we superimpose the observed net Ginis, which thereby is indicative of the deviation of expected net income inequality under RRMR from observed net inequality. The largest of such deviations for our sample of countries by far are found in Chile (19 points on the Gini index), followed by Russia (10.5 points), Turkey (10 points) the United States (between 6.5 and 4 points) and Israel (4.5 points). The range of simulated net Ginis under MVT is quite narrow, whereas the range of observed net Ginis is much broader.

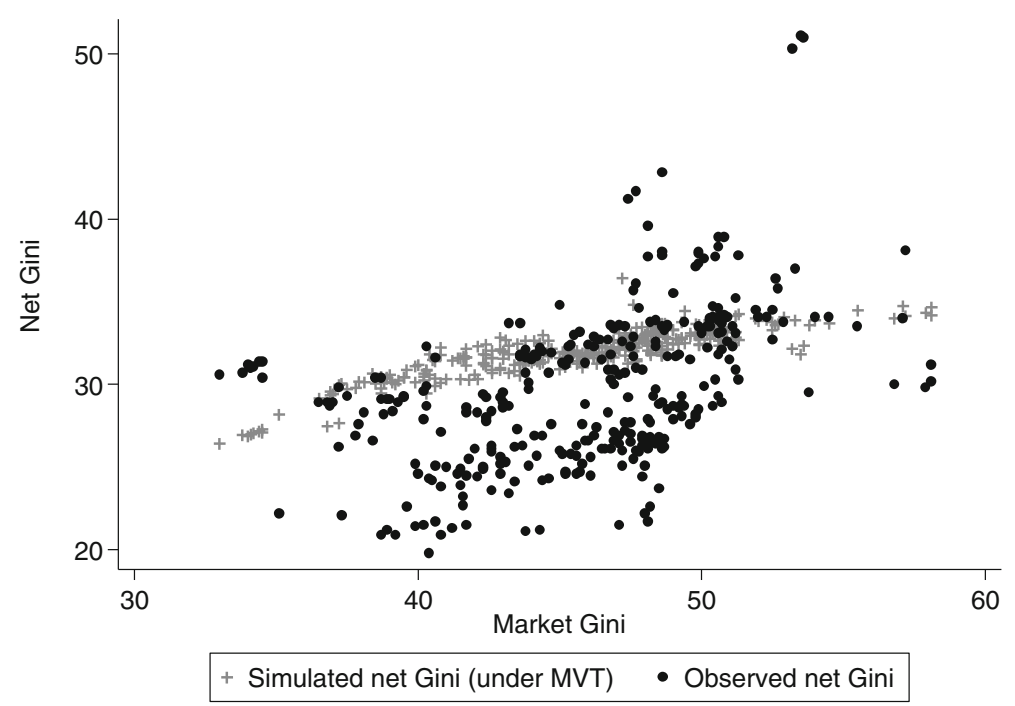

Fig. 5 Association between net Gini (simulated and observed) and market Gini 
This analysis makes clear three subsets of countries exist. A first subset is situated below the expected net Gini under the MVT, consisting of among others the Scandinavian countries, Slovenia, Czech Republic and Belgium. The second subset aligns with the expectation, including countries such as Australia and Canada on the one hand, and Estonia and Poland on the other. For the final subset of countries, net income inequality exceeds that expected under the RRMR framework, among others Turkey, Russia and the United States.

Potentially, there are numerous factors that might explain the variation in the position of the decisive voter relative to the median voter. We already noted that between countries this variation is twice as large as within countries over time (see Table 1), so it is natural to look for an explanation that focuses on differences between countries. Although it is beyond the scope of this study to do a full-fledged investigation of factors relevant for the positioning of the decisive voter, we choose to evoke the seminal work The Three Worlds of Capitalism by Esping-Andersen (1990) to see whether this well-documented taxonomy of welfare states is borne out in our estimates. Welfare state regimes each supplement the market economy with a legal framework extending social rights to citizens, but in different ways. The ideal typical liberal welfare state champions economic growth and efficiency, designing its social programs so as to avoid work disincentives and welfare dependency. The corporatist regime aims at social stability and social integration (taken as the opposite of social exclusion), with occupational social insurance as its predominant transfer program, focusing on the position of breadwinners contingent on the occurrence of unemployment, disability and sickness. The social democratic regime, finally, gives priority to minimizing poverty, income inequality and unemployment, largely by means of tax-financed universal benefits and active labour market policies.

In Fig. 6, we have pitched our measure of the MVD against the tax rate $\hat{t}$ for the final observed year to see if the type of welfare state matters. All liberal welfare states are indeed situated at the right corner, combining relatively low tax rates with percentile positions $P$ of the decisive voter well above 50. All social democratic regimes are in the upper left corner, combining high tax rates with values for $P$ below the median. Corporatist welfare states Germany, France and Austria are situated in between these liberal and social democratic clusters, flanked by Italy and Spain on the right and Belgium on the left. Regarding $\hat{t}$, this latter welfare state type resembles the social democratic type, yet on average at a MVD closer to zero. Differences between these two types, in other words, largely play out on the MVD axis.

Besides the type of welfare state, another natural candidate to explain the variation in the position of the decisive voter is the phenomenon of skewed voter turnout, that is voter turnout tends to increase with income. Larcinese (2007) tries to improve the performance of the RRMR model by including voter turnout as an explanatory variable. Larcinese (2007) shows that to explain social expenditures as a percentage of GDP, voting turnout is positively significant whereas the ratio of median to mean income is insignificant. Kenworthy and Pontusson (2005: 459) also find that voter turnout is positively significant to explain redistribution, leading them to speculatively state 'the Meltzer-Richard model accurately identifies the distribution of market income and voter turnout as key variables in the politics of redistribution'. Looking at Table 4, if the hypothesis that skewed voter turnout shifts the effective median voter to the right in the income distribution holds, then we expect the higher our estimate of the position of the decisive voter, the more skewed voter turnout will be. For this analysis, ideally one requires voter turnout by income decile. 


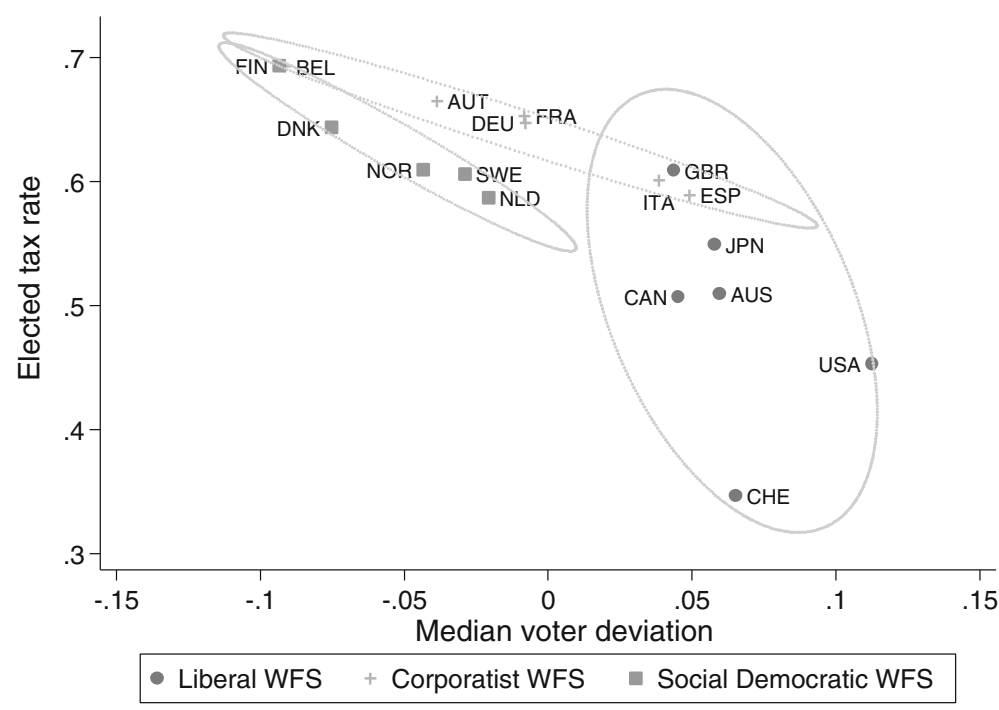

Fig. 6 The tax rate and median voter deviation for the three welfare state (WFS) types from Worlds of Welfare

\section{Conclusion}

Recent rises in income and wealth inequality have led authors to question standing economic models predicting higher inequality will be met with increased redistribution. While most of these models evoke the MVT to ascertain the expected level of taxation, we set out to empirically retrieve the position of the decisive voter based on the observed gross and net Gini coefficients.

Combining data on gross and net income inequality and making a number of simplifying assumptions - in particular that gross income is lognormally distributed, that redistribution can be modelled as a flat tax-lump sum transfer, that voters choose their optimal tax rate and that the labour supply elasticity is constant across countries and time - allows us to estimate both the extent to which nations redistribute and the location of the decisive income earner. Using the information of the Gini coefficients for the gross and net income distribution, we find that on average the tax rate required to align the observed gross and net Gini coefficient is the tax rate that the median earner would prefer. This suggests that in the OECD, on average, the decisive voter is the median voter. Our method can be used to identify the decisive voter in non-OECD countries, as soon as reliable data becomes available for these countries. Although the MVT on average holds for the OECD, within this group of democratic and economically developed nations, diffuse patterns continue to persist. We show the taxonomy of welfare states into three types aligns with our findings.

Our method allows promising avenues for future efforts to study the relationship between political institutions and inequality, both between countries and within countries over time. We provide a framework in which better estimates of parameters, for example country- and time-specific elasticities of labour supply, or lifting some of our assumptions, e.g. allowing a non-linear tax-and-transfer scheme, can be included. Future work may also consider different distributions beyond the lognormal, testing the robustness of our estimates of the 
positions of the decisive voters to different distributional assumptions, such as the Weibull, Fisk or Gamma distributions.

Acknowledgments We are grateful for the comments by the referees and the editor, which helped us to improve the paper considerably.

Open Access This article is distributed under the terms of the Creative Commons Attribution 4.0 International License (http://creativecommons.org/licenses/by/4.0/), which permits unrestricted use, distribution, and reproduction in any medium, provided you give appropriate credit to the original author(s) and the source, provide a link to the Creative Commons license, and indicate if changes were made.

\section{Appendix 1: Derivation of the parameters for the lognormal distribution of net income under different tax rates}

Gross income $x$ is the product of one's wage rate and labour supply, given the tax rate $\hat{t}$ in place:

$$
x=w L^{*}=\left[\frac{1-\hat{t}}{(1-\hat{t}) w_{m}}\right]^{\eta} w^{1+\eta} .
$$

Median labour supply is normalized to one for the given tax rate $\hat{t}$. Wages are lognormally distributed according to $w \sim L N\left(\mu, \sigma^{2} /(1+\eta)^{2}\right)$ (see Table 1). We can calculate the distribution of gross wages under a different tax rate $t^{\prime}$, noting $x$ then becomes a transformation of wages of the type $a \cdot w^{b}$, where $a=\left[\frac{1-t^{\prime}}{(1-\hat{t}) w_{m}}\right]^{\eta}$ and $b=1+\eta$. This gives the following distribution of $x$ :

$$
x \sim \operatorname{LN}\left(\mu(1+\eta)+\ln \left(\frac{1-t^{\prime}}{(1-\hat{t}) w_{m}}\right)^{\eta}, \sigma^{2}\right) .
$$

If $t^{\prime}=\hat{t}$, from Eq. 24 it then follows that $x \sim L N\left(\mu, \sigma^{2}\right)$. In order to find the distribution of net income $y$ under $t^{\prime}$, we use the fact that the median net earner is the same individual as the median gross earner, giving $y_{m}=\left(1-t^{\prime}\right) x_{m}+f-g$. This can subsequently be rewritten as

$$
e^{\mu_{n}}=\left(1-t^{\prime}\right) e^{\mu(1+\eta)+\eta \ln \left(\frac{1-t^{\prime}}{(1-\hat{t}) w_{m}}\right)}+\left(t^{\prime}-t_{g}\right) e^{\mu(1+\eta)+\eta \ln \left(\frac{1-t^{\prime}}{(1-\hat{t}) w_{m}}\right)+\sigma^{2} / 2}
$$

which, when solved for $\mu_{n}$ gives:

$$
\mu_{n}=\mu(1+\eta)+\eta \ln \left(\frac{1-t^{\prime}}{(1-\hat{t}) w_{m}}\right)+\ln \left[\left(1-t^{\prime}\right)+\left(t^{\prime}-t_{g}\right) e^{\sigma^{2} / 2}\right] .
$$

In order to derive the variance parameter of the distribution of net income $\sigma_{n}^{2}$, we use the fact that $\left(1-t_{g}\right) \bar{x}=\bar{y}$, which can be written as:

$$
\left(1-t_{g}\right) e^{\mu(1+\eta)+\eta \ln \left(\frac{1-t^{\prime}}{(1-t) w_{m}}\right)+\sigma^{2} / 2}=e^{\mu_{n}+\sigma_{n}^{2} / 2} .
$$

Solving for $\sigma_{n}^{2}$ gives:

$$
\sigma_{n}^{2}=2\left[\ln \left(1-t_{g}\right)+\mu(1+\eta)+\eta \ln \left(\frac{1-t^{\prime}}{(1-\hat{t}) w_{m}}\right)+\frac{\sigma^{2}}{2}-\mu_{n}\right] .
$$


Substitution of Eqs. 26 into 28 gives the following expression of $\sigma_{n}^{2}$

$$
\sigma_{n}^{2}=\sigma^{2}-2\left[\ln \left[\left(1-t^{\prime}\right)+\left(t^{\prime}-t_{g}\right) e^{\sigma^{2} / 2}\right]-\ln \left(1-t_{g}\right)\right] .
$$

We can simulate a net Gini for any given level of $t^{\prime}$ using the square root of Eq. 29:

$$
G_{n}=2 \Phi\left(\frac{\sigma_{n}}{\sqrt{2}}\right)-1 .
$$

Using this method, the reconstituted net Gini $G_{n}(\hat{t})$ highly correlates with the observed net Gini $G_{n}(\rho=0.993)$.

\section{References}

Aitchison, J., Brown, J.A.C.: The Lognormal Distribution: with Special Reference to its Uses in Economics. University Press, Cambridge (1957)

Arawatari, R.: Informatization, voter turnout and income inequality. J. Econ. Inequal. 7(1), 29-54 (2009)

Aronson, J.R., Johnson, P., Lambert, P.J.: Redistributive effect and unequal income tax treatment. Econ. J. 104(423), 262-270 (1994)

Bonica, A., McCarty, N., Poole, K.T., Rosenthal, H.: Why hasn't democracy slowed rising inequality. J. Econ. Perspect. 27(3), 103-24 (2013)

Chotikapanich, D., Valenzuela, R., Rao, D.: Global and regional inequality in the distribution of income: estimation with limited and incomplete data. Empir. Econ. 22(4), 533-546 (1997)

Damgaard, C., Weiner, J.: Describing inequality in plant size or fecundity. Ecology 81(4), 1139-1142 (2000)

Dikhanov, Y., Ward, M.: Evolution of the global distribution of income in 1970-99. In: Proceedings of the global poverty workshop initiative for policy dialogue. Columbia University, New York (2002)

Evers, M., de Mooij, R., van Vuuren, D.: The wage elasticity of labour supply: a synthesis of empirical estimates. De Economist 156(1), 25-43 (2008)

Esping-Andersen, G.: The Three Worlds of Welfare Capitalism. Polity Press, Cambridge (1990)

Harms, P., Zink, S.: Limits to redistribution in a democracy: a survey. Eur. J. Polit. Econ. 19(4), 651-668 (2003)

Jenkins, S.P.: Reranking and the analysis of income redistribution. Scott. J. Polit. Econ. 35(1), 65-76 (1988)

Jenkins, S.P.: World income inequality databases: an assessment of WIID and SWIID. J. Econ. Inequal. 13(4), 629-671 (2015)

Karabarbounis, L.: One dollar, one vote. Econ. J. 121(553), 621-651 (2011)

Kenworthy, L., Pontusson, J.: Rising inequality and the politics of redistribution in affluent countries. Perspect. Polit. 3(3), 449-471 (2005)

Larcinese, V.: Voting over redistribution and the size of the welfare state: the role of turnout. Polit. Stud. 55(3), 568-585 (2007)

Lubrano, M.: The econometrics of inequality and poverty, lecture 4, http://www.vcharite.univ-mrs.fr/PP/ lubrano/cours/Lecture-4.pdf (2015)

Mahler, V.A.: Electoral turnout and income redistribution by the state: a cross-national analysis of the developed democracies. Eur. J. Polit. Res. 47(2), 161-183 (2008)

Meltzer, A.H., Richard, S.F.: A rational theory of the size of government. J. Polit. Econ. 89(5), 914-927 (1981)

Mettler, S.: The Submerged State: How Invisible Government Policies Undermine American Democracy. University of Chicago Press, Chicago (2011)

McDonald, J.B.: Some generalized functions for the size distribution of income. Econometrica 52(3), 647663 (1984)

Milanovic, B.: True world income distribution, 1988 and 1993: first calculation based on household surveys alone. Econ. J. 112(476), 51-92 (2002)

OECD: Income Distribution database (IDD). OECD, Paris (2015)

Piketty, T.: Capital in the Twenty-First Century. The Belknap Press of Harvard University Press, Cambridge (2014)

Pinkovskiy, M., Sala-i-Martin, X.: Parametric estimations of the world distribution of income, NBER Working Paper Number 15433 (2009) 
Roemer, J.E., Aaberge, R., Colombino, U., Fritzell, J., Jenkins, S.P., Lefranc, A., Marx, I., Page, M., Pommer, E., Ruiz-Castillo, J., Jesus San Segundo, M., Tranaes, T., Trannoy, A., Wagner, G.G., Zubiri, I.: To what extent do fiscal regimes equalize opportunities for income acquisition among citizens. J. Public Econ. 87(3), 539-565 (2003)

Scervini, F.: Empirics of the median voter: democracy, redistribution and the role of the middle class. J. Econ. Inequal. 10(4), 529-550 (2012)

Singh, S.K., Maddala, G.S.: A function for the size distribution of incomes. Econometrica 44(5), 963-970 (1976)

Van Zanden, J.L., Baten, J., Foldvari, P., van Leeuwen, B.: The changing shape of global inequality 18202000; exploring a new dataset. Rev. Income Wealth 60(2), 279-297 (2014)

World Bank: World development indicators. World Bank, Washington DC (2015) 